\title{
PRODUÇÃO E QUALIDADE DA FORRAGEM DE CORNICHÃO SOBRESSEMEADO EM DIFERENTES DENSIDADES DE SEMEADURA EM PASTAGEM DE ESTRELA AFRICANA E AZEVÉM
}

\author{
PRODUCTION AND QUALITY OF FORAGE OF BIRDSFOOT OVERSEEDING IN \\ DIFFERENT DENSITIES IN PASTURE OF CYNODON NLENFUENSIS AND \\ RYEGRASS
}

\author{
Magali Floriano da SILVEIRA ${ }^{1}$; Ana Maria Osório DIAS ${ }^{2}$; \\ Luís Fernando Glasenapp de MENEZES ${ }^{1}$; Clederson MARTINELLO ${ }^{4}$; Douglas VONZ ${ }^{3}$; \\ Nakali Evelize CAREGNATTO ${ }^{4}$ \\ 1. Professor, Universidade Tecnológica Federal do Paraná, Dois Vizinhos, PR, Brasil. magalisilveira@utfpr.edu.br; 2. Aluna do \\ Doutorado no Programa de Pós-graduação em Zootecnia da Universidade Federal de Santa Maria, Santa Maria, RS, Brasil; 3. \\ Zootecnista, MSc. em Zootecnia pela Universidade Tecnológica Federal do Paraná, Dois Vizinhos, Brasil; 4. Alunos de graduação em \\ Zootecnia, Universidade Tecnológica Federal do Paraná, Dois Vizinhos, Brasil.
}

\begin{abstract}
RESUMO: O objetivo deste trabalho foi avaliar o potencial produtivo e as características qualitativas de uma pastagem de cornichão semeado em diferentes densidades de semeadura em mistura com estrela africana e azevém. Os tratamentos avaliados foram: 0, 50, 100, 150 e 200\% a mais da quantidade de semente de cornichão recomendada. Para a semeadura do cornichão e do azevém foram utilizados 6 e $30 \mathrm{~kg} / \mathrm{ha}$ de semente conforme recomendação, respectivamente. Ambas as espécies foram sobressemeadas na pastagem de estrela africana que já se encontrava estabelecida na área. $\mathrm{O}$ delineamento experimental utilizado foi o inteiramente casualizado com cinco tratamentos e quatro repetições. A produção total de matéria seca foi semelhante entre as densidades de semeadura avaliadas. A produção de cornichão se ajustou ao modelo quadrático, sendo que as densidades de 50 e $100 \%$ a mais da recomendação apresentaram as menores produções de forragem. A taxa de acúmulo e as produções individuais das espécies não foram influenciadas pelos tratamentos. A produção total de MS foi superior para o mês de dezembro, e as menores produções para os meses de agosto, setembro e outubro, sendo intermediário para o mês de janeiro. A composição botânica entre as espécies do consórcio diferiu entre os meses avaliados. Para estrela africana e azevém os teores de PB foram similares e o teor de PB para cornichão foi superior entre as espécies avaliadas. A utilização de 150 e $200 \%$ a mais da recomendação da densidade de semeadura do cornichão aumenta a sua produção de forragem, porém não afeta a produção total de forragem do consórcio.
\end{abstract}

PALAVRAS-CHAVE: Consórcio. Cynodon nlenfuensis. Lotus corniculatus. Lolium multiflorum. Produção de forragem. Taxa de acúmulo da forragem.

\section{INTRODUÇÃO}

A produção de forragem ao longo do ano não atende de forma constante as exigências nutricionais dos animais, devido principalmente, à estacionalidade na sua produção, sendo um dos fatores responsáveis pela baixa produtividade da pecuária brasileira. Uma das formas de otimizar a produção forrageira no período hibernal seria a utilização de consórcios que visem prolongar o período de utilização da pastagem bem como melhorar a sua qualidade. Desta forma, o consórcio entre gramíneas tropicais, temperadas e leguminosas, atende a estes princípios (ABREU et al., 2005).

A região sudoeste do Paraná apresenta grande potencial na produção leiteira, sendo que no período de dez anos considerados pelo Censo Agropecuário do IBGE (1996-2006) (SEAB 2007) a produção de leite da região cresceu $132 \%$ e por estabelecimento aumentou 200,1\%, bem acima da média nacional e estadual. Estas propriedades possuem como base forrageira os cultivares de gramíneas do gênero Cynodon, entre elas, a grama estrela cv. Africana. Esta gramínea apresenta alta taxa fotossintética, com produtividade de matéria seca superior a plantas forrageiras de clima temperado, porém não toleram baixas temperaturas. Assim, a sobressemeadura de espécies anuais de inverno, como o azevém, oferecem produção de forragem no período em que a gramínea tropical cessa seu crescimento, mantendo uma produção de matéria seca constante ao longo do ano para os animais.

Tanto para gramíneas tropicais e temperadas, o nutriente que mais limita o seu crescimento é o nitrogênio $(\mathrm{N})$, refletindo em menor capacidade de suporte da pastagem. Portanto, verifica-se uma dependência no uso de adubação nitrogenada para o aumento da produtividade dos 
pastos, o que reflete em aumento dos custos de produção. Uma forma de minimizar os custos e ofertar $\mathrm{N}$ para as gramíneas é a utilização de leguminosas, as quais fixam $\mathrm{N}_{2}$, representando uma importante fonte renovável de $\mathrm{N}$ que pode ajudar a manter e aumentar a fertilidade do solo em benefício dos cultivos subseqüentes e reduzindo o uso de fertilizante nitrogenado (ASSMANN et al., 2004). Dados comprovam que o uso de leguminosas reduz a aplicação de fertilizantes, diversifica a dieta do animal, além de melhor a qualidade da pastagem (SKONIESKI et al. 2011).

Dentre as leguminosas hibernais, o cornichão (Lotus corniculatus L.) apresenta versatilidade, tolerância à acidez e à baixa fertilidade do solo e não provoca timpanismo (SOSTER et al. 2004). Porém, as pesquisas que visam seu estabelecimento em sobressemeadura com gramíneas tropicais e temperadas, são escassas.

Sabe-se que muitos fatores influenciam o crescimento das espécies no consórcio, entre eles a seleção dos cultivares, competição entre os componentes da mistura e a densidade de semente (FRIZZO et al. 2003). Poucos estudos são conduzidos com o objetivo de determinar a densidade de semeadura adequada no plantio do cornichão em consórcio com outras espécies.

Portanto, o objetivo deste estudo foi avaliar a produção e as características bromatológicas do cornichão sobressemeado em diferentes densidades na estrela africana em consórcio com azevém.

\section{MATERIAL E MÉTODOS}

O experimento foi realizado na Universidade Tecnológica Federal do Paraná (UTFPR) - Câmpus Dois Vizinhos - PR, localizada no terceiro planalto Paranaense, possui altitude de $520 \mathrm{~m}$, latitude de $25^{\circ} 44^{\prime}$ " Sul e longitude de " $53^{\circ} 04^{\prime}$ " W Oeste, a 520 metros acima do nível do mar. O experimento foi conduzido na Unidade de Ensino e Pesquisa de Bovinocultura de Leite (UNEP). A pesquisa foi conduzida entre maio de 2009 e janeiro de 2010. A região apresenta clima do tipo subtropical úmido mesotérmico ( $\mathrm{Cfa}$ ), segundo a classificação de Köppen. O solo é classificado como Nitosolo vermelho distroférrico de textura argilosa, desenvolvido a partir de rochas eruptivas básicas, sendo profundo, bem drenado, com coloração vermelho-escura e textura argilosa (EMBRAPA, 1999). O relevo configura-se como ondulado a suave ondulado.

O delineamento experimental utilizado foi inteiramente casualizado com quatro repetições, sendo que cada repetição era constituída de parcelas com tamanho de $6 \mathrm{~m}^{2}$ (3x2m) e espaçamento entre parcelas de $1 \mathrm{~m}$. As coletas das amostras foram realizadas no centro da parcela, sendo o restante considerado bordadura e descartadas da avaliação. As avaliações foram realizadas nos dias 21/08; 21/09; 23/10; 04/12 e 15/01/2010.

As espécies utilizadas foram o cornichão (Lotus corniculatus L.), e o azevém (Lolium multiflorum), ambos sobressemeados em pastagem de estrela africana (Cynodon nlemfuensis), sendo que a densidade de semeadura utilizada foi de 6 $\mathrm{kg} / \mathrm{ha}$ por hectare de semente de cornichão e para o estabelecimento do azevém foi utilizado $30 \mathrm{~kg} / \mathrm{ha}$ em todas as parcelas. Os tratamentos avaliados foram às diferentes densidades de semente de cornichão: $0,50,100,150$ e $200 \%$ a mais da recomendação indicada representando, respectivamente, $3,6,9$ e $12 \mathrm{~kg} / \mathrm{ha}$ de semente e o testemunha contendo somente a estrela africana e o azevém (0 kg).

A pastagem de estrela-africana foi pastejada por vacas em lactação. No final do verão, a pastagem foi rebaixada através do pastejo a $10 \mathrm{~cm}$ de altura para a semeadura do azevém. $\mathrm{O}$ azevém foi semeado a lanço. No momento da semeadura, ainda não havia ocorrências de geadas na região, sendo que esta ocorreu na primeira quinzena de julho.

Quando a pastagem atingiu $30 \mathrm{~cm}$ de altura, cortes foram realizados rente ao solo com o auxílio de uma tesoura e um quadrado de $0,25 \mathrm{~m}^{2}$, retirando-se uma amostra, posteriormente as amostras foram pesadas para a estimativa de produção de forragem (PF) total por hectare. $\mathrm{O}$ restante da parcela foi rebaixado a $10 \mathrm{~cm}$ com auxílio de roçadeira manual. A forragem proveniente dos cortes foi homogeneizada e dividida em duas sub-amostras, uma para a determinação da matéria seca do pasto e outra para a determinação do percentual de cada espécie no consórcio.

A primeira sub-amostra utilizada para determinar o teor de matéria seca, foi acondicionada em sacos de papel e levados a estufa com circulação forçada a $65^{\circ} \mathrm{C}$ por um período de 72 horas. A segunda sub-amostra foi separada de acordo com as espécies encontradas no consórcio, e desta forma, foi calculada a participação, em percentual, do cornichão, azevém e estrela africana. Após foram acondicionadas em sacos de papel e levados a estufa com circulação forçada a $65^{\circ} \mathrm{C}$ por um período de 72 horas. Todas as amostras foram posteriormente moídas em moinho tipo Willey com peneira de 1 $\mathrm{mm}$ e acondicionadas em sacos plásticos para posterior análise bromatológica.

Para a determinação da composição química das amostras, foi determinado o teor de matéria seca 
(MS), por secagem em estufa a $105^{\circ} \mathrm{C}$ durante pelo ao menos oito horas. $\mathrm{O}$ teor de nitrogênio total $(\mathrm{N})$ foi determinado pelo método de Kjeldahl (método 984.13, AOAC, 1995). As análises bromatológicas foram realizadas no Laboratório de Bromatologia da Universidade Tecnológica Federal do Paraná, Câmpus Dois Vizinhos.

Os dados coletados foram submetidos à análise de variância e teste $\mathrm{F}$ em nível de $5 \%$ de significância. As densidades de semeadura representavam as parcelas principais, e os cortes (agosto, setembro, outubro, dezembro e janeiro) às subparcelas. Avaliou-se a interação entre estes efeitos, e as médias quando apresentaram efeito dos cortes foi avaliado pelo teste de Tukey, e o efeito das densidades de sementes foi avaliado por meio de regressão a 5\% de probabilidade (SAS, 2001).

\section{RESULTADOS E DISCUSSÃO}

Não houve significância para a interação entre os efeitos densidade $\mathrm{x}$ corte para as variáveis estudadas. A produção total de matéria seca (Tabela 1) foi semelhante entre os tratamentos testados. Esta similaridade pode ter ocorrido, pelo fato que, o consórcio foi constituído por três espécies que se alternavam na produção de forragem ao longo do período experimental. Além disso, foi constituído por leguminosa, o que pode ter favorecido o crescimento das gramíneas, pois Pedreira (2001) verificou que o consórcio entre gramíneas e leguminosas melhora a disponibilidade de forragem pelo aporte de nitrogênio ao sistema por meio de sua reciclagem e transferência para a gramínea acompanhante. Desta forma, a maior produção de matéria seca das leguminosas aumenta a fixação de
$\mathrm{N}_{2}\left(\mathrm{~g} \mathrm{~N} / \mathrm{m}^{2}\right)$ como verificado no trabalho de Gierus et al. (2012), isto se deve principalmente pelo aumento da produção de raízes. Além disso, muitos fatores podem influenciar o crescimento das espécies utilizadas no consórcio, entre eles, destacase: a seleção dos cultivares, a densidade de semente e a competição entre os componentes da mistura (CARR et al., 2004). Desta forma, verifica-se que as condições foram ideais para o crescimento de ambas as espécies

A produção de cornichão se ajustou ao modelo de regressão quadrático, sendo que as densidades de 50 e $100 \%$ da recomendação apresentaram as menores produções de forragem, ocorrendo provavelmente pela maior presença da estrela africana neste consórcio (Tabela 1). Heinrichs et al. (2001) observaram que a ervilhaca apresentou baixa capacidade de competição com a aveia em um experimento que avaliaram o desempenho destas espécies em cultivo solteiro ou consorciado em diferentes proporções de semeadura.

A taxa de acúmulo (kg.ha ${ }^{-1}$ dia $^{-1}$ de MS) não foi influenciada pelas diferentes densidades de semeadura $(\mathrm{P}>0,05)$ (Tabela 1). Esperava-se que com o aumento da densidade de semeadura do cornichão haveria um maior acúmulo de forragem, pelo fato de haver maior disponibilidade de nutrientes, principalmente nitrogênio $(\mathrm{N})$. No entanto, verifica-se que apesar do aumento na densidade de semeadura, a participação do cornichão nas densidades testadas ficou similar, com média de $22,7 \%$, sendo que a possível contribuição na fixação de $\mathrm{N}$ pela leguminosa foi igual para todas as densidades avaliadas.

Tabela 1. Rendimento total de matéria seca (MS), rendimento de MS da estrela africana (Rendimento EA), rendimento de MS do azevém (Rendimento $\mathrm{AZ}$ ), rendimento de MS do cornichão (Rendimento Corn) e taxa de acúmulo e composição botânica (\%) de acordo com a densidade de cornichão no consórcio.

\begin{tabular}{|c|c|c|c|c|c|c|}
\hline \multirow{2}{*}{ Variáveis } & \multicolumn{5}{|c|}{ Densidade de semeadura } & \multirow{2}{*}{$\mathrm{P}>\mathrm{F}$} \\
\hline & $\mathbf{0}$ & $\mathbf{5 0}$ & 100 & 150 & 200 & \\
\hline Rendimento de MS (kg.ha ${ }^{-1}$ de MS) & 10174,4 & 9516,5 & 8035,2 & 10800,7 & 11403,2 & NS \\
\hline Rendimento EA (kg.ha- ${ }^{-1}$ de MS) & 9800,3 & 8533,5 & 7065,6 & 9534,4 & 9454,3 & NS \\
\hline Rendimento AZ (kg.ha ${ }^{-1}$ de MS) & 7713,9 & 7391,1 & 6329,6 & 8273,9 & 8252,0 & NS \\
\hline Rendimento CORN (kg.ha ${ }^{-1}$ de MS) ${ }^{\mathrm{a}}$ & 7434,0 & 3221,6 & 3211,4 & 7656,2 & 8764,3 & $*$ \\
\hline Taxa de acúmulo (kg.ha ${ }^{-1}$ dia $^{-1}$ de MS) & 71,3 & 65,2 & 57,7 & 74,3 & 85,8 & NS \\
\hline \multicolumn{7}{|l|}{ Composição botânica } \\
\hline Estrela africana (\%) & 76,06 & 55,4 & 51,6 & 44,5 & 44,2 & NS \\
\hline Azevém (\%) & 19,3 & 24,3 & 28,1 & 29,9 & 23,9 & NS \\
\hline Cornichão (\%) & - & 23,1 & 19,7 & 21,7 & 26,5 & NS \\
\hline
\end{tabular}

${ }^{\mathrm{a}} \mathrm{Y}=6975,2-68,9 \mathrm{x}+0,41 \mathrm{x}^{2}, \mathrm{P}=0,0079 ; \mathrm{r}^{2}=0,11$ 
Observa-se entre as densidades de semeadura testadas, a presença do cornichão foi semelhante a do azevém $(\mathrm{P}<0,05)$, porém, é importante ressaltar que em sistemas de pastejo, devido ao seu hábito de crescimento ereto, a sua sobrevivência diminui. No Uruguai, a principal restrição para a produtividade de forragem é a falta de persistência (REBUFFO, 2005). Outro problema apresentado por esta leguminosa é a dificuldade de perenização, sendo que a flutuação na proporção de leguminosas em consórcio com gramíneas é a principal preocupação agronômica, refletindo em alterações na produtividade e na qualidade nutricional da mistura com a grama companheira, especialmente para pastos que não são fertilizados com $\mathrm{N}$ mineral (GIERUS et al., 2012).

A produção total de MS do cornichão nas densidades de 150 e $200 \%$ da recomendação foi superior a relatada por Rocha et al. (2007), que encontraram produção de $6.6627,3 \mathrm{~kg} / \mathrm{MS} / \mathrm{ha}$, no entanto, o autor citado atribuiu a baixa produção de MS a um déficit hídrico que ocorreu durante o período vegetativo. No Uruguai a produção acumulada do cornichão cv. São Gabriel durante três anos foi de $24.658 \mathrm{~kg} / \mathrm{ha}$ (CAMPS; CASTRO; BOGGIANO, 2009) e em campos nativos sobressemeados com a espécie, de 11,8 t MS/há (OLMOS, 2001). Scheffer-Basso et al. (2002) relataram produções de $13.663 \mathrm{~kg}$ MS/há em mistura com Festuca arundinacea Schreb.
As participações das espécies no consórcio não variaram em função das diferentes densidades de semeadura do cornichão $(\mathrm{P}>0,05)$. Abreu et al. (2005) verificaram menor rendimento médio de grãos, redução no perfilhamento e na biomassa de aveia branca nas maiores populações de plantas.

Porém, o nível nutricional individual da pastagem de estrela africana se tornou menor do que as parcelas que continham cornichão sobressemeado, devido à falta da leguminosa que contribui diretamente na transferência de $\mathrm{N}$.

$\mathrm{Na}$ produção de azevém $\left(\mathrm{kg} \cdot \mathrm{ha}^{-1}\right.$ de MS), observa-se que sua produção foi constante mesmo com o aumento das densidades do cornichão.

A produção total de MS foi diferente significativamente entre os meses dos cortes avaliados ( $\mathrm{P}<0,05$; Tabela 2$)$, apresentando menor produção para os meses de agosto a outubro, e superior para o mês de dezembro, seguido por janeiro. Esta superioridade na produção total de MS foi causada pela maior participação da estrela africana e do cornichão no consórcio, pois podemos observar que as maiores participações destas espécies ocorrerão nestes meses (Tabela 2).

A estrela africana, por ser uma espécie tropical, concentra sua produção na temporada primavera-verão. Por outro lado, o azevém tem seu pico de produção durante o inverno com seu rendimento mais elevado no início da primavera (SANTOS et al. 2009).

Tabela 2. Rendimento total de matéria seca $\left(\mathrm{kg}_{\mathrm{ha}}{ }^{-1}\right.$ de $\left.\mathrm{MS}\right)$, rendimento de MS da estrela africana (Rendimento EA) (kg.ha- ${ }^{-1}$ de MS), rendimento de MS do azevém (Rendimento AZ) $\left(\mathrm{kg} \cdot \mathrm{ha}^{-1} \mathrm{de}\right.$ $\mathrm{MS}$ ), rendimento de MS do cornichão (Rendimento Corn) ( $\mathrm{kg}_{\mathrm{gha}}{ }^{-1} \mathrm{de} \mathrm{MS}$ ) e taxa de acúmulo e composição botânica (\%) de acordo com os meses.

\begin{tabular}{|c|c|c|c|c|c|}
\hline \multirow{2}{*}{ Variáveis $^{1}$} & \multicolumn{5}{|c|}{ Cortes } \\
\hline & Agosto & Setembro & Outubro & Dezembro & Janeiro \\
\hline Rendimento MS & $1876,5 \mathrm{c}$ & $1291,3 c$ & $1407,8 \mathrm{c}$ & $6136,5 \mathrm{a}$ & $3491,9 b$ \\
\hline Rendimento EA (kg.ha ${ }^{-1}$ de MS) & $649,9 \mathrm{c}$ & $529,3 \mathrm{c}$ & $828,0 \mathrm{c}$ & $3856,0 \mathrm{a}$ & $2733,1 \mathrm{~b}$ \\
\hline Rendimento AZ (kg.ha ${ }^{-1}$ de MS) & $1025,6 \mathrm{a}$ & $602,9 b$ & $182,9 \mathrm{c}$ & - & - \\
\hline Rendimento CORN (kg.ha ${ }^{-1}$ de MS) & 1143,4 & 976,1 & 738,1 & 4491,4 & 1220,0 \\
\hline Taxa de acúmulo (kg.ha ${ }^{-1}$ dia $^{-1}$ de MS) & $20,8 \mathrm{~d}$ & $43,0 \mathrm{~cd}$ & $45,4 \mathrm{c}$ & $146,1 \mathrm{a}$ & $116,4 \mathrm{~b}$ \\
\hline \multicolumn{6}{|l|}{ Composição botânica } \\
\hline Estrela africana (\%) & $31,2 \mathrm{c}$ & $42,3 b c$ & $59,6 a b$ & $64,5 \mathrm{a}$ & $78,5 \mathrm{a}$ \\
\hline Azevém (\%) & $57,6 \mathrm{a}$ & $46,4 \mathrm{a}$ & $14,0 \mathrm{~b}$ & - & - \\
\hline Cornichão (\%) & $2,3 \mathrm{c}$ & $6,2 \mathrm{bc}$ & $19,7 \mathrm{ab}$ & $27,2 \mathrm{a}$ & $17,8 \mathrm{ab}$ \\
\hline
\end{tabular}

${ }^{1}$ Médias seguidas de letras diferentes, nas linhas, diferem entre si pelo teste Tukey a 5\% de probabilidade.

A estrela africana aumentou sua produção de MS à medida que avançou os dias no período experimental $(\mathrm{P}<0,05$; Tabela 2$)$, totalizando uma produção média de $8.840,8 \mathrm{~kg} \cdot \mathrm{ha}^{-1}$ de MS. Alvim et al. (2003), verificaram produção anual da estrela africana de 18.609 e 21.739 kg/MS há ${ }^{-1}$, respectivamente utilizando duas doses de $\mathrm{N}: \mathrm{K}_{2} \mathrm{O}$.

A produção do azevém a partir do mês de dezembro foi nula, sendo que sua produção acabou em meados de outubro, o que era esperado, pois é 
uma planta de ciclo hibernal com período de utilização de 60 a 180 dias (SANTOS et al., 2009). A partir deste período permaneciam no consórcio apenas a estrela africana e o cornichão. A produção do azevém foi superior no mês agosto, intermediária no mês de setembro e inferior em outubro. Avaliando duas frequiências de corte (3 vs 5 cortes) Gierus et al. (2012) também verificaram redução na produção de MS total (712 vs $571 \mathrm{~g} \mathrm{MS} / \mathrm{m}^{2}$, respectivamente) com o aumento da freqüência de cortes.

A produção de cornichão não foi afetada $(\mathrm{P}<0,05)$ pelo número de cortes realizados. Mas verifica-se uma produção satisfatória comparada a outras pesquisas (GIERUS et al. 2012; ROCHA et al. 2007). Scheffer-Basso et al (2011) avaliando oito genótipos de cornichão, verificaram redução nos atributos morfológicos quando submetidos a um curto intervalo de corte, e isto indica que $\mathrm{o}$ cornichão apresenta uma rebrota lenta. Comparando a estacionalidade do acúmulo de MS entre $A$. Latifolia e cornichão, a primeira alcançou seu patamar produtivo aos 2.902 graus-dias (GD) enquanto o cornichão precisou acumular 630 GD a mais para a mesma disponibilidade de forragem
(280 g MS $/ \mathrm{m}^{2}$ ) (SCHEFFER-BASSO et al., 2001), indicando mais uma vez, que é uma espécie tardia.

A composição botânica entre as espécies do consórcio foi influenciada pelo aumento no número de cortes. No primeiro corte, o azevém predominava no consórcio, diminuindo ao longo do período de avaliação, por outro lado, a estrela africana foi aumentando sua participação, uma vez que, se aproximava da época de primavera-verão, momento pelo qual alcança o período vegetativo, período de maior produção (Tabela 2).

$\mathrm{O}$ teor de proteína bruta $(\mathrm{PB})$ foi superior para o cornichão $(19,2 \%$ PB) em comparação a estrela africana e azevém, porém entre estas espécies houve similaridade $(13,4$ e $14 \%$ PB, respectivamente) (Tabela 3). Quando se avaliou o teor de PB em relação aos cortes, também foi verificada diferença significativa $(\mathrm{P}<0,05)$ entre os meses avaliados. $\mathrm{O}$ teor de $\mathrm{PB}$ foi mais alto para o mês de setembro, porém não diferiu dos meses de outubro e dezembro. Teores de PB similares foi encontrado nos meses de agosto, outubro, dezembro e janeiro para as espécies avaliadas.

Tabela 3. Médias para proteína bruta $(\mathrm{PB}, \%)$ da pastagem de estrela africana, azevém e cornichão, de acordo com os cortes

\begin{tabular}{lrrrrrl}
\hline \multirow{2}{*}{ Espécies $^{1}$} & \multicolumn{5}{c}{ Cortes } & \multirow{2}{*}{ Média } \\
\cline { 2 - 6 } & Agosto & Setembro & Outubro & Dezembro & Janeiro & \\
\hline Azevém & 11,9 & 15,4 & 12,6 & - & - & $13,4 \mathrm{~b}$ \\
Estrela & 12,1 & 16,2 & 14,4 & 14,6 & 12,4 & $14,0 \mathrm{~b}$ \\
Conichão & 19,3 & 22,6 & 21,1 & 17,0 & 16,1 & $19,2 \mathrm{a}$ \\
& & & & & \\
Média & $13,5 \mathrm{~b}$ & $17,8 \mathrm{a}$ & $15,7 \mathrm{ab}$ & $15,7 \mathrm{ab}$ & $14,1 \mathrm{~b}$ & \\
\hline
\end{tabular}

${ }^{1}$ Médias seguidas de letras diferentes, na linha e coluna, diferem entre si pelo teste Tukey a $5 \%$ de probabilidade.

Podemos observar que no mês de setembro, havia maior participação do azevém, seguido pela estrela africana, sendo que a participação da leguminosa foi irrisória $(2,3$ e $6,2 \%$, respectivamente), no entanto, foi decisiva para elevar o teor de PB nos meses iniciais. Skonieski et al. (2011) ao estudarem o valor nutricional de pastagens de azevém consorciado com trevo-branco observaram que o maior teor de PB encontrado no período inicial da pastagem foi devido a maior participação da leguminosa, em torno de $25 \%$ de biomassa com 35 dias. Nos meses de agosto, outubro, dezembro e janeiro, houve um menor teor de PB. Durante o mês de agosto, este menor valor pode ter sido devido à presença de folhas senescentes oriundas da estrela africana, uma vez que esta, não estava no período vegetativo, e para o mês de outubro, houve uma redução neste teor pela presença de colmos e folhas senescentes provenientes do azevém que se encontrava em final de ciclo. Para o mês de dezembro ocorreu um déficit hídrico que provocou a redução do teor de PB na estrela africana. $\mathrm{O}$ crescimento vegetal é reduzido quando ocorre estresse hídrico, e desta forma, aumenta a proporção de tecidos estruturais e a espessura das paredes celulares, diminuindo os teores de $\mathrm{PB}$ e elevando os teores de fibra detergente neutro (FDN) e a digestibilidade da planta (WILSON, 1982).

Ribeiro et al. (2008) estudando a influência da irrigação sobre a digestibilidade in vivo de nutrientes de pastos de capimmombaça e capim-elefante, verificaram que a digestibilidade da PB foi mais alta para o 
capim-mombaça do que o capim-elefante para os pastos não-irrigados, enquanto que para os pastos irrigados a digestibilidade da PB foi similar. A porcentagem de PB é mais elevada no início do período, independente do uso da consorciação entre gramíneas e leguminosas, assim como há maior digestibilidade no início, devido ao crescimento das forragens (DIFANTE et al. 2006).

$\mathrm{O}$ teor de PB foi reduzido no mês de janeiro, devido à redução na proporção de folhas e incremento na proporção de hastes das plantas. Soster et al. (2004) avaliando diferentes genótipos de cornichão encontraram os maiores valores nos cortes que corresponderam ao estádio vegetativo, devido a maior relação folha:haste, característica deste estádio de desenvolvimento, e menores teores de $\mathrm{PB}$ nos dois últimos cortes que corresponderam, respectivamente, aos estádios de florescimento e frutificação.

\section{CONCLUSÕES}

A utilização de 150 e $200 \%$ a mais da recomendação da densidade de semeadura do cornichão aumenta a sua produção de forragem, porém não afeta a produção total de forragem do consórcio.

O teor de proteína bruta foi maior durante o período vegetativo das espécies do consórcio.

\begin{abstract}
The objective of study was evaluate the performance productive and the qualitative characteristics of pasture birdsfoot sown with different seeding densities in mixture with ryegrass and Cynodon nlenfuensis. The trataments evaluated was: 0, 50, 100, 150 and 200\% the more the amount of seed birdsfoot recommended. For seeding birdsfoot and ryegrass were used 6 and $30 \mathrm{~kg} / \mathrm{ha}$ seed as recommended, respectively. Both species were overseeded pasture Cynodon nlenfuensis who was already established in the area. The experimental design was completely randomized with five treatments and four replications. The total dry matter production was similar between plant densities evaluated. The production of birdsfoot adjusted to the quadratic model, with densities of 50 and $100 \%$ more of the recommendation had the lowest forage production. The accumulation rate $\left(\mathrm{kg} \mathrm{DM}^{-1} \mathrm{ha}^{-1} \mathrm{dia}\right)$ and the production of individual species (kg DM / ha) were not influenced by different plant densities. The total dry matter production was higher for the month of december, and decrease productions for months of august, september and october, is intermediate for the month january. The botanical composition of the consortium species differed between the evaluated months. For Cynodon nlenfuensis and ryegrass the $\mathrm{CP}$ were similar and the content $\mathrm{CP}$ for birdsfoot was higher among species evaluated. The use of 150 and $200 \%$ more the proportion of recommended seeding rate of birdsfoot increased forage production, but did not affect the total forage production consortium.
\end{abstract}

KEYWORDS: Accumulation daily forage rate. Consortium, Cynodon nlenfuensis. Forage production. Lolium multiflorum. Lotus corniculatus.

\title{
REFERÊNCIAS
}

ABREU, G. T.; SCHUCH, L. O. B.; MAIA, M. de S.; ROSENTHAL, M. D.; BACCHI, S.; PEREIRA, É.; CANTARELLI, L. D.; Produção de biomassa em consórcio de aveia branca (Avena sativa L.) e leguminosas forrageiras. Revista Brasileira de Agrociência, Pelotas, v. 11, n. 1, p. 19-24, 2005.

ASSMANN, A. L.; PELISSARI, A.; MORAES, A.; ASSMANN T. S.; OLIVEIRA, E. B.; SANDINI, I.; Produção de gado de corte e acúmulo de matéria seca em sistema de integração lavoura-pecuária em presença e ausência de trevo branco e nitrogênio. Revista Brasileira de Zootecnia, Viçosa, v. 33, n. 1, p. 37-44, 2004.

ASSOCIATION OF OFFICIAL ANALYTICAL CHEMISTS. Official methods of analysis. 12 ed. Washington, D. C., 1995.

CARR, P. M., HORSLEY, R. D., POLAND, W. W. Barley, oat and cereal-pea mixtures as dryland forages in the Northern Great Plains. Agronomy Journal, Madison, v. 96, p. 677-684, 2004.

http://dx.doi.org/10.2134/agronj2004.0677 
CAMPS, G.; CASTRO, M.; BOGGIANO, P. Revisión de la red de ensayos de evaluación de cultivares de espécies forrajeras. Disponível em: <http://www.inia.org.uy/convenio_inase_inia/fpta222.pdf >. Data de acesso em: 15/03/2013.

COSTA, N. L.; OLIVEIRA, J. R. C. Efeito do diferimento sobre o rendimento e composição de leguminosas forrageiras nos Cerrados de Rondônia. Pasturas Tropicales, Santiago de Cali, v. 14, n. 1, p. 28-31, 1992.

DIFANTE, G. S.; MARCHEZAN, E.; VILLA, S. C. C.; ROCHA, M. G.; SANTOS, F. M.; CAMARGO, E. R. Produção de novilhos de corte com suplementação em pastagem de azevém submetida a doses de nitrogênio. Revista Brasileira de Zootecnia, Viçosa, v. 35, n. 3, p. 1107-1113, 2006.

EMBRAPA, Centro Nacional de Pesquisa de Solo (Rio de Janeiro, RJ). Sistema Brasileiro de Classificação de Solos. Rio de Janeiro, 412p, 1999.

FONTANELI, R. S.; SANTOS, H. P; FONTANELI, R. S.; OLIVEIRA, J. T. Forrageiras para integração lavoura-pecuária-floresta na região sul-brasileira. In: SANTOS, H.P; FONTANELI, R.S.; FONTANELI, R. S.; OLIVEIRA, J. T. Gramíneas anuais de inverno. Passo Fundo: Embrapa Trigo, 2009, 340p.

FRIZZO, A.; ROCHA, M. G.; RESTLE, J.; FREITAS, M. R.;GEORGIA BISCAÍNO, G.; ALCIDES PILAU, A. Produção de forragem e retorno econômico da pastagem de aveia e azevém sob pastejo com bezerras de corte submetidas a níveis de suplementação energética. Revista Brasileira de Zootecnia, Viçosa, v. 32, n. 3, p. 632-642, 2003;

GIERUS, M.; KLEEN, J.; LOGES, R.; TAUBES, F. Forage legumes species determine the nutritional quality of binary mixtures with perennial ryegrass in the first production years. Animal Feed Science and

Technology, Madri, v. 172, p. 150-161, 2012.

GOVERNO DO ESTADO DO PARANÁ SECRETARIA DE ESTADO DA AGRICULTURA E DO

ABASTECIMENTO - SEAB. Cenário Atual da Pecuária de Corte, Aspectos do Brasil com Foco no Estado do Paraná, Ano 2007 Cenário Atual da Pecuária de Corte - Aspectos do Brasil com Foco no Estado do Paraná Ano 2007 - Fabio Peixoto Mezzadri. - Curitiba: SEAB/DERAL/DCA, 2007.

HEINRICHS, R.; AITA, C.; AMADO, T. J. C. et al. Cultivo consorciado de aveia e ervilhaca: relação C/N da fitomassa e produtividade do milho em sucessão. Revista Brasileira da Ciência do Solo, Viçosa, v. 25, p. 331340, 2001

INSTITUTO AGRONÔMICO DO PARANÁ. Cartas climáticas do Estado do Paraná 1994. Londrina: IAPAR, 49p. 1994.

OLMOS, F. L. Mejoramiento de pasturas con Lotus en La Región Noreste. Montevideo: INIA, 2001. 48p. (Série Técnica n 124 ).

PEDREIRA, G. S. P.; MELLO, A. C. L.; OTANI, L. O processo de produção em pastagens. In: REUNIÃO ANUAL DA SOCIEDADE BRASILEIRA DE ZOOTECNIA, 38., 2001, Piracicaba. Anais... Piracicaba: Fundação de Estudos Agrários Luiz de Queiroz, 2001. p. 772-807.

REBUFFO, M. Plant breeding: Lotus corniculatus and Lotus uliginosus. Lotus Newsletter, Montevideo, v. 35, n. 1, p. 9-10, 2005.

RIBEIRO, E. G.; FONTES, C. A. A.; PALIERAQUI, J. G. B.; MARTINS, C. E.; CÓSER, A. C.; SANT’ANA, N.F. Influência da irrigação durante as épocas seca e chuvosa na taxa de lotação, no consumo e no desempenho de novilhos em pastagens de capim-elefante e capim-mombaça. Revista Brasileira de Zootecnia, Viçosa, v. 37, n. 9, p. 1546-1554, 2008. 
ROCHA, M. G.; QUADROS, F. L. F.; GLIENKE, C. L.; CONFORTIN, A. C. C.; COSTA,V. G.; ROSSI, G. E. Avaliação de espécies forrageiras de inverno na Depressão Central do Rio Grande do Sul. Revista Brasileira de Zootecnia, Viçosa, v. 36, n. 6, p. 1990-1999, 2007.

SAS INSTITUTE. SAS/STAT user's guide: statistics. 4.ed. Version 6, Cary: v. 2, 2001.

SCHEFFER-BASSO, S. M.; BRUSTOLIN, R.; DALL'AGNOL, M. Performance of Lotus corniculatus L. genotypes submitted to cutting interval: subsidies to a breeding program. Revista Brasileira de Zootecnia, Viçosa, v. 40, n. 8, p. 1645-1650, 2011.

SCHEFFER-BASSO, S. M.; VENDRÚSCULO, M. C.; BARÉA, K. BENINCÁ, R. C.; Lubenow, R.; CECCHETTI, D. Comportamento de leguminosas (Adesmia, Lotus, Trifolium) em mistura com Festuca. Revista Brasileira de Zootecnia, Viçosa, v. 31, n. 6, p. 2197-2203, 2002.

SCHEFFER-BASSO, S. M.; VOSS, M.; JACQUES, A. V. A. Nodulação e fixação biológica de nitrogênio de Adesmia latifólia e Lotus corniculatus em vasos de Leonard. Revista Brasileira de Zootecnia, Viçosa, v. 30, n. 3, p. 687-693, 2001.

SKONIESKI, F. R.; VIÉGAS, J.; BERMUDES, R. F.; NÖRNBERG,J. L.; ZIECH, M. F.; COSTA, O. A. D.; MEINERZ, G. R.; Composição botânica e estrutural e valor nutricional de pastagens de azevém consorciadas. Revista Brasileira de Zootecnia, Viçosa, v. 40, n. 3, p. 550-556, 2011.

SOSTER, M. T. B; SCHEFFER-BASSO, S. M; DALL'AGNOL, M.; Caracterização Morfofisiológica de Genótipos de Cornichão (Lotus corniculatus L.) Revista Brasileira de Zootecnia, Viçosa, v. 33, n. 6, p. 16541661, 2004 (Supl. 1).

WILSON, J. R. Environmental and nutritional factors affecting herbage quality. In: HACKER, J. B. (Ed.). Nutritional limits to animal production from pastures. Sta. Lucia: Commonwealth Agricultural Bureaux, 1982. p. 111-131. 